\title{
Mapping Wind Speed Changes
}

\author{
Rui Mao, Cuicui Shi, Qi Zong, Xingya Feng, Yijie Sun, Yufei Wang, \\ and Guohao Liang
}

\section{Introduction}

Wind variability has a major impact on water cycles, wind energy, and natural hazards and disasters such as hurricanes and typhoons. In the past decades, the global and regional mean near-surface wind speed (sfcWind) has shown a significantly downward trend, especially in the mid-latitudes in the Northern Hemisphere (Wu et al. 2018). The global mean terrestrial sfcWind has decreased linearly at a rate of $0.08 \mathrm{~m} \mathrm{~s}^{-1}$ per decade during 1981-2011. Vautard et al. (2010) analyzed changes in sfcWind at stations across the globe and found that $73 \%$ of the total stations presented a decrease in the annual mean sfcWind, with linear trends of $-0.09, \quad-0.16,-0.12$, and $-0.07 \mathrm{~m} \mathrm{~s}^{-1}$ per decade in Europe, Central Asia, East Asia, and North America, respectively. In addition, a pronounced reduction in extreme sfcWind has also been observed in Europe and the United States (Yan et al. 2002; Pryor et al. 2012). However, because long-term observational data are lacking in most land areas

Authors: Rui Mao, Cuicui Shi, Qi Zong, Xingya Feng, Yijie Sun, Yufei Wang, Guohao Liang.

Map Designers: Fanya Shi, Yelin Sun, Tian Liu, Jing'ai Wang, Ying Wang.

Language Editor: Rui Mao.

R. Mao $(\bowtie) \cdot$ C. Shi $\cdot$ Q. Zong · X. Feng · Y. Sun · Y. Wang .

G. Liang

Faculty of Geographical Science, Beijing Normal University,

Beijing, 100875, China

e-mail:mr@bnu.edu.cn

R. Mao $\cdot$ C. Shi $\cdot$ Q. Zong $\cdot$ X. Feng $\cdot$ Y. Sun $\cdot$ Y. Wang $\cdot$ G. Liang

State Key Laboratory of Earth Surface Processes and Resource

Ecology, Faculty of Geographical Science, Beijing Normal

University, Beijing, 100875, China

R. Mao $\cdot$ C. Shi $\cdot$ Q. Zong $\cdot$ X. Feng $\cdot$ Y. Sun $\cdot$ Y. Wang $\cdot$ G. Liang

Key Laboratory of Environmental Change and Natural Disaster,

Ministry of Education, Beijing Normal University, Beijing,

100875, China and oceans, the uncertainty in the long-term trend of sfcWind is high, particularly in the Southern Hemisphere and over oceans.

The Coupled Model Intercomparison Project Phase 5 (CMIP5) aims to understand the past climate changes, make projections, and estimate future uncertainties. For example, with respect to the historical period (1979-2005), the multi-model ensemble mean of simulations in the CMIP5 projects a decrease in the annual maximum wind speeds at the end of this century (2074-2100) over the contiguous United States and most regions of Asia in the high latitudes and an increase in the annual maximum wind speeds over Amazonia, India, Africa, and Southeast Asia, whereas few changes are projected to occur over Europe (Kumar et al. 2015). It is worth noting that studies on extreme wind speed in Asia, Africa, and South America as well as those on mean sfcWind over the Southern Hemisphere by using the CMIP5 simulations are lacking. Moreover, the uncertainty analysis in regional mean sfcWind and extreme wind speed in the CMIP5 results is ignored in previous studies. For example, the CMIP5 models fail to represent the current wind climate over the Bay of Bengal (Krishnan and Bhaskaran 2019) and show relatively poor skill for the long-term temporal trends over the Northern Hemisphere (Tian et al. 2019).

To achieve a comprehensive understanding of the changes in global sfcWind and extreme wind speed in the future and their uncertainties in the results of CMIP5 models, this section initiatively assesses the changes of the mean state, variance, and extreme conditions of sfcWind under three greenhouse gas emission scenarios (Representative Concentration Pathway (RCP2.6, RCP4.5, RCP8.5). 


\section{Data}

The global average daily sfcWind and daily maximum sfcWind data are provided by the Coupled Model Intercomparison Project Phase 5 (CMIP5) from the World Climate Research Programme (WRCP), where daily sfcWind includes 24 models for the historical period and RCP4.5 and RCP8.5 scenarios and 16 models for the RCP2.6 scenario, and daily maximum sfcWind includes 19 models for historical period and RCP4.5 and RCP8.5 scenarios and 11 models for RCP2.6 scenario. The spatial resolution of the data is 0.5 degrees $(\sim 50 \mathrm{~km} \times 50 \mathrm{~km})$. The CMIP5 data can be freely accessed on this website: https://esgf-node.llnl. gov/search/cmip5/.

\section{Method}

We divided the temporal range into three periods, including the historical period (1986-2005, denoted as the 2000s), and two future time periods: 2016-2035 (2030s) and 2046-2065 (2050s). In this study, summer is defined as June-JulyAugust (JJA), and winter is defined as December and January-February of the following year (DJF).

The mean near-surface wind speed (sfcWind) is defined as the 20-year mean of all daily near-surface wind speed for the historical period and the two future time periods under the three RCP scenarios. The sfcWind change was calculated by subtracting the sfcWind during the historical period (2000s) from that under the RCP scenarios in the future temporal ranges. The model uncertainty of the mean sfcWind is represented by the standard deviation of the mean sfcWind across the models for the three periods.

The near-surface wind speed variability (sfcWind std) is defined as the standard deviation of the daily mean near-surface wind speed during the three periods. The change in sfcWind variability was calculated by subtracting the sfcWind std during the historical period (2000s) from the sfcWind std under the RCP scenarios in the future temporal ranges. The model uncertainty of the sfcWind std is represented by the standard deviation of the sfcWind std for the three periods across the models.
The maximum near-surface wind speed (sfcWindmax) mean is defined as the 20-year mean of all daily maximum near-surface wind speed for the historical period and the two future time periods under the three RCP scenarios. The sfcWindmax change was calculated by subtracting the sfcWindmax during the historical period (2000s) from the sfcWindmax under the RCP scenarios in the future temporal ranges. The model uncertainty of the mean sfcWindmax is represented by the standard deviation of the mean sfcWindmax for the three periods across the models.

The maximum near-surface wind speed variability (sfcWindmax std) is defined as the standard deviation of the daily mean maximum near-surface wind speed during the three periods. The change in sfcWindmax variability was calculated by subtracting the sfcWindmax std during the historical period (2000s) from the sfcWindmax std under the RCP scenarios in the future temporal ranges. The model uncertainty of the sfcWindmax std is represented by the standard deviation of the sfcWindmax std for the three periods across the models.

Because of the varying spatial resolutions of the simulations in the CMIP5, the variables are interpolated by using a bilinear interpolation with a high spatial resolution of $0.5^{\circ} \times 0.5^{\circ}$.

\section{Major Findings}

Surface wind speed, surface wind speed variability, and surface maximum wind speed in nine global regions under climate change are shown in Figs. 1, 2 and 3. In general, under the climate warming scenarios, the surface wind speed increases in North Asia, the Mediterranean Basin, Tibet, and Eastern North America, and decreases in low latitude areas, such as Northern Australia and the Amazon Basin. Compared with the historical period, the interannual variability of wind speed will increase. However, with climate warming, the interannual variation of surface wind speed will be different in different regions - it is projected to decrease in the Mediterranean Basin and Tibet, and increase in the Amazon Basin and Southeast Asia. The overall change of the surface maximum wind speed is not obvious, and only in Tibet and the Mediterranean Basin it will decrease with the climate change. 


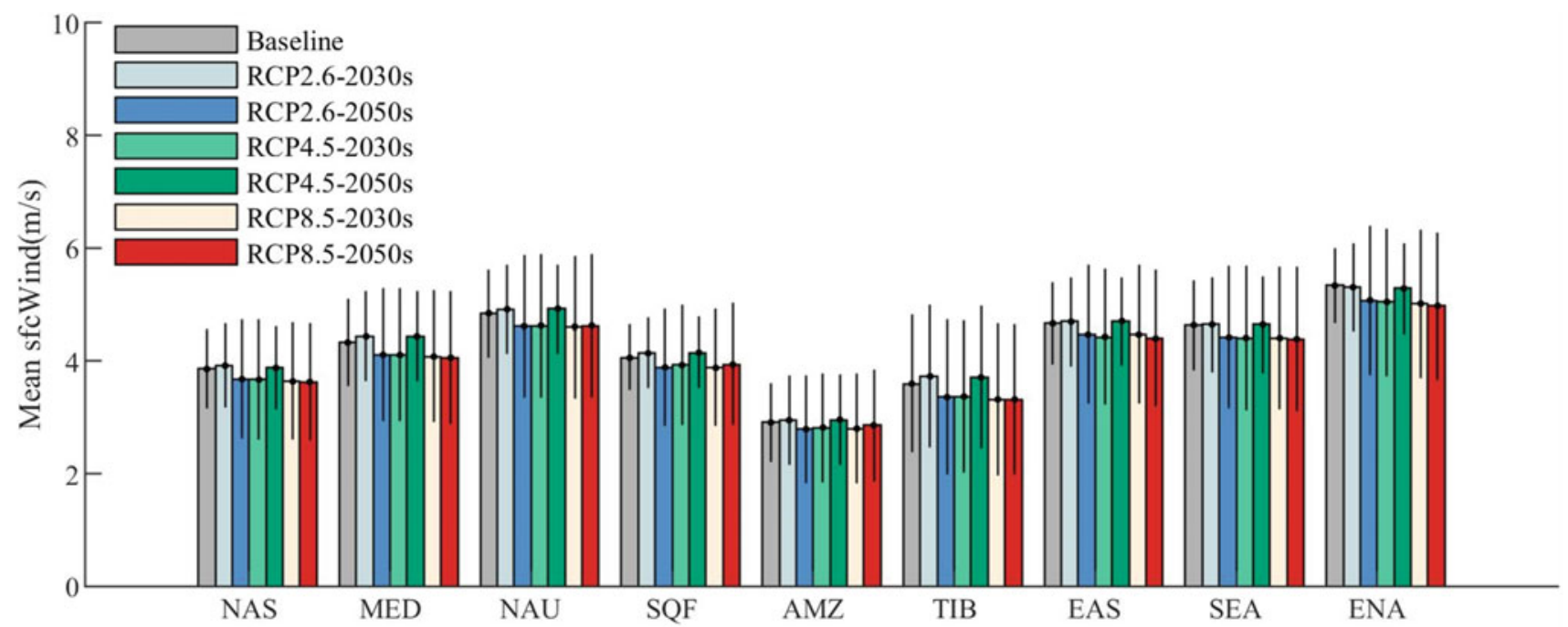

Fig. 1 Mean surface wind speed (unit: $\mathrm{m} / \mathrm{s}$ ) in nine regions under different Representative Concentration Pathway (RCP) scenarios. The error bar represents the one standard deviation across 16 general circulation models (GCMs) (RCP2.6) and 24 GCMs (RCP4.5 and RCP8.5). NAS, MED, NAU, SQF, AMZ, TIB, EAS, SEA, and ENA represent North Asia $\left(47-70^{\circ} \mathrm{N}, 60.5-180.5^{\circ} \mathrm{E}\right)$, Mediterranean Basin $\left(30-47^{\circ} \mathrm{N}, 10.5^{\circ} \mathrm{W}-37.5^{\circ} \mathrm{E}\right)$, Northern Australia $\left(28-10^{\circ} \mathrm{S}, 109.5-\right.$ $\left.155.5^{\circ} \mathrm{E}\right)$, South Equatorial Africa $\left(26-0^{\circ} \mathrm{S}, 0.5-55.5^{\circ} \mathrm{E}\right)$, Amazon Basin $\left(20^{\circ} \mathrm{S}-10^{\circ} \mathrm{N}, 78.5-34.5^{\circ} \mathrm{W}\right)$, Tibet $\left(30-47^{\circ} \mathrm{N}, 80.5-104.5^{\circ} \mathrm{E}\right)$, East Asia $\left(20-47^{\circ} \mathrm{N}, 104.5-140.5^{\circ} \mathrm{E}\right)$, Southeast Asia $\left(10^{\circ} \mathrm{S}-20^{\circ} \mathrm{N}\right.$, $\left.100.5-150.5^{\circ} \mathrm{E}\right)$, and Eastern North America $\left(25-50^{\circ} \mathrm{N}, 85.5-60.5^{\circ} \mathrm{W}\right)$, respectively. Regional division follows Giorgi and $\mathrm{Bi}$ (2005)

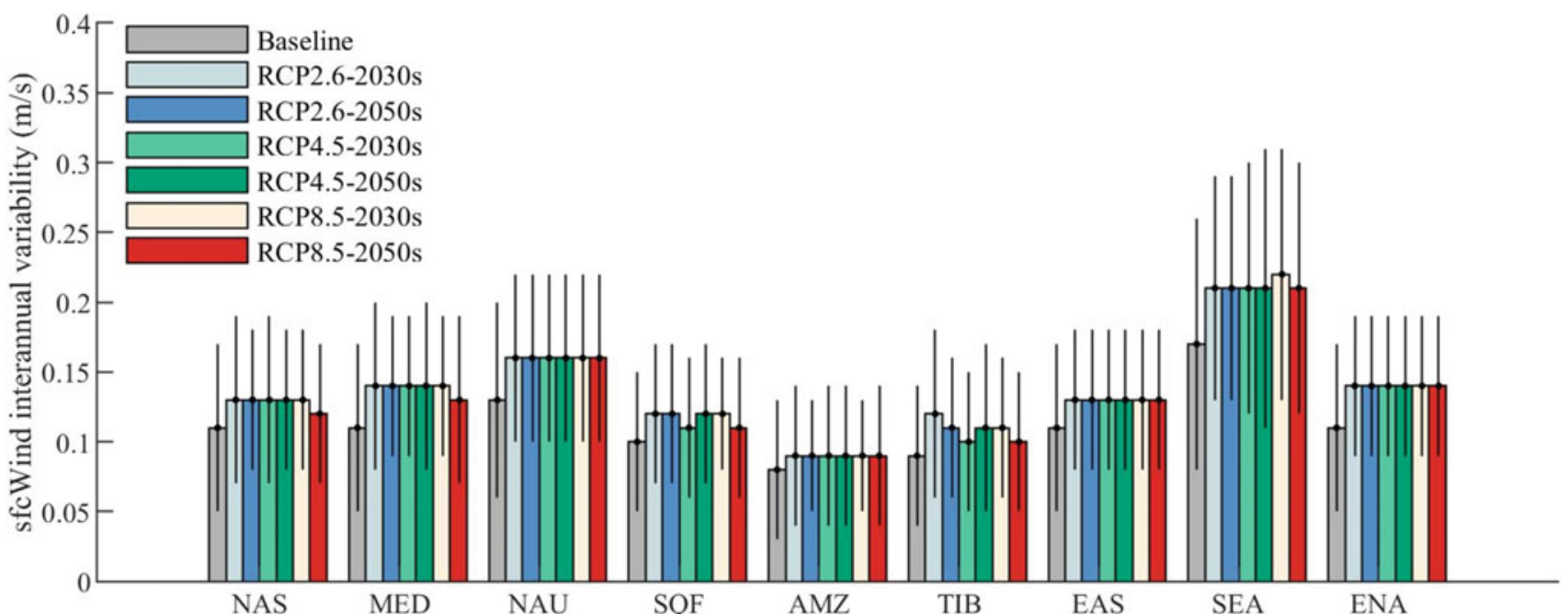

Fig. 2 Variability of mean surface wind speed (unit: $\mathrm{m} / \mathrm{s}$ ) in nine regions under different Representative Concentration Pathway (RCP) scenarios. The error bar represents the one standard deviation

across 16 general circulation models (GCMs) (RCP2.6) and 24 GCMs (RCP4.5 and RCP8.5). Region abbreviations are the same as in Fig. 1 


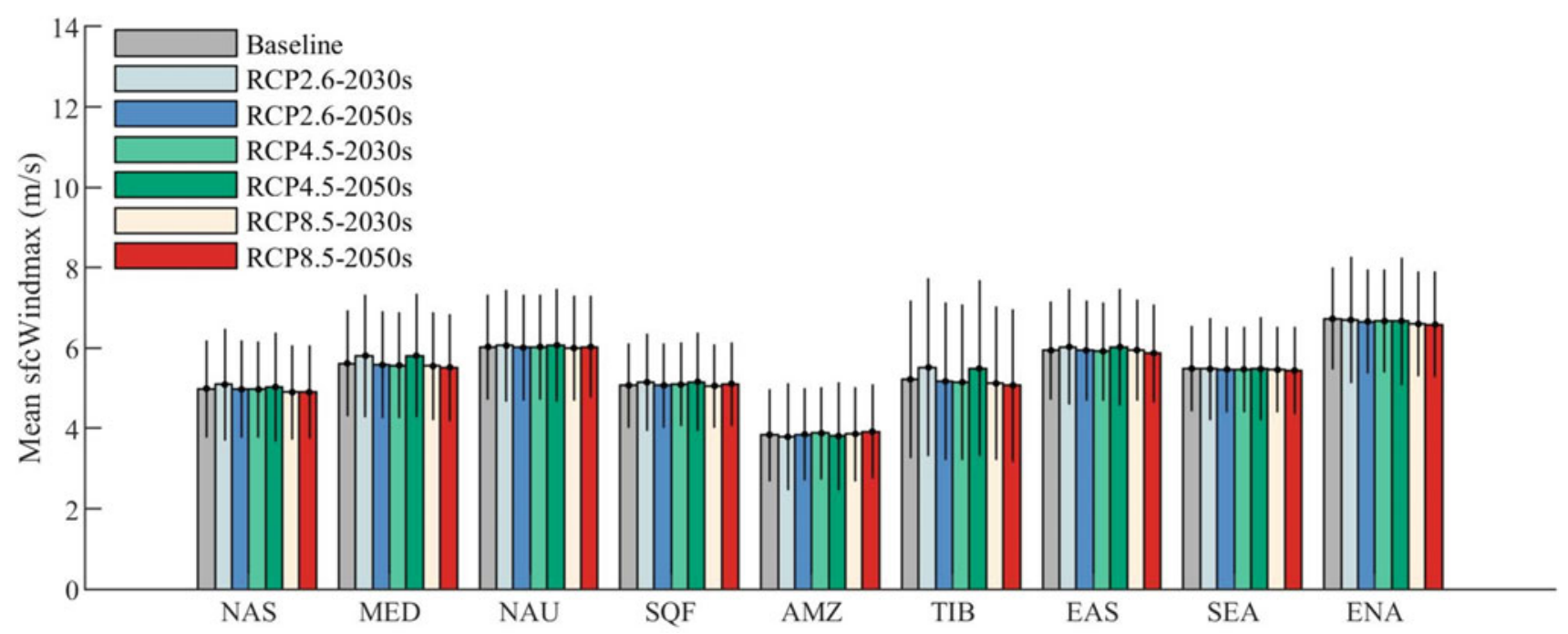

Fig. 3 Surface maximum wind speed (unit: $\mathrm{m} / \mathrm{s}$ ) in nine regions under different Representative Concentration Pathway (RCP) scenarios. The circulation models (GCMs) (RCP2.6) and 19 GCMs (RCP4.5 and error bar represents the one standard deviation across 11 general RCP8.5). Region abbreviations are the same as in Fig. 1 


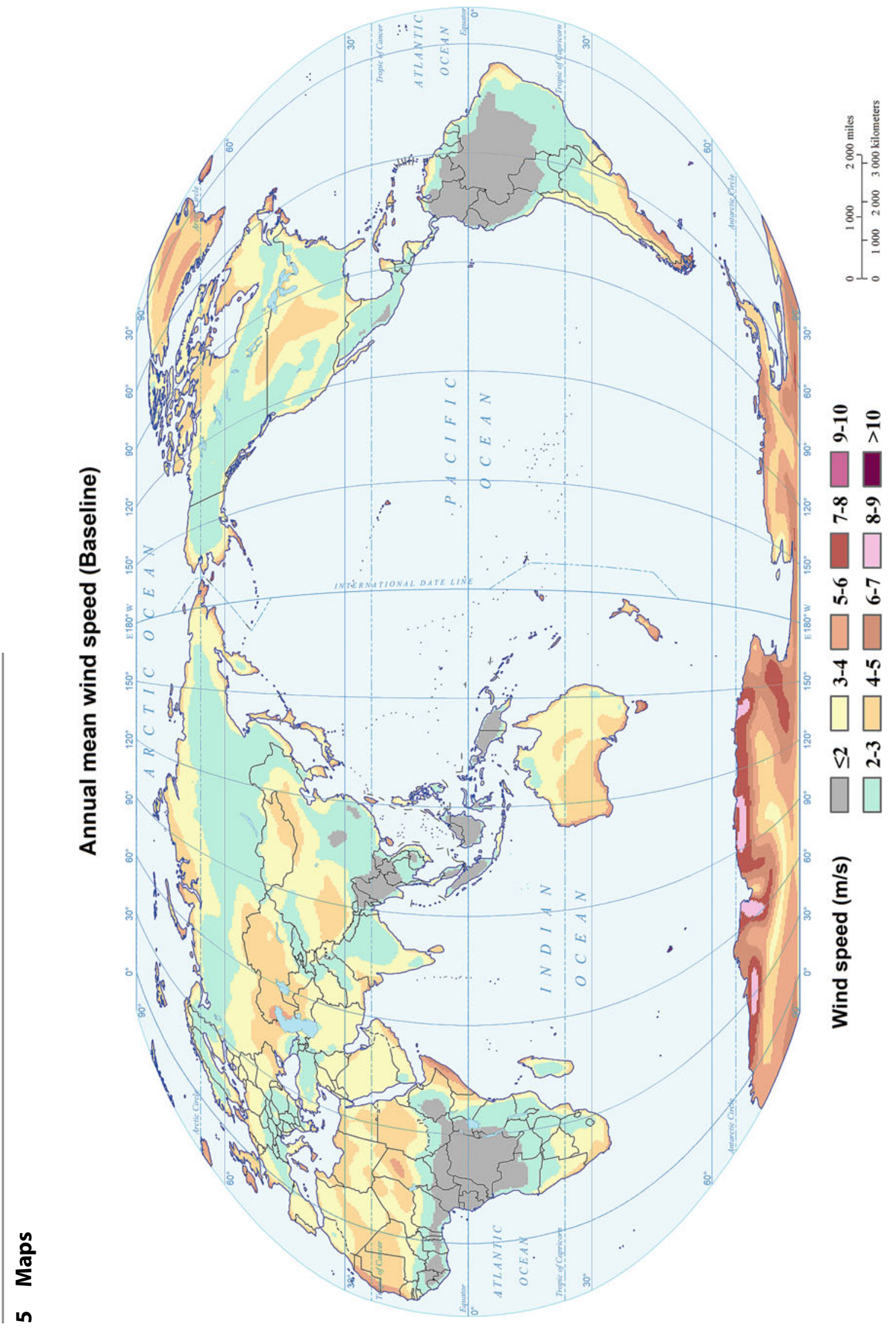


Annual mean wind speed (2030s, RCP2.6)

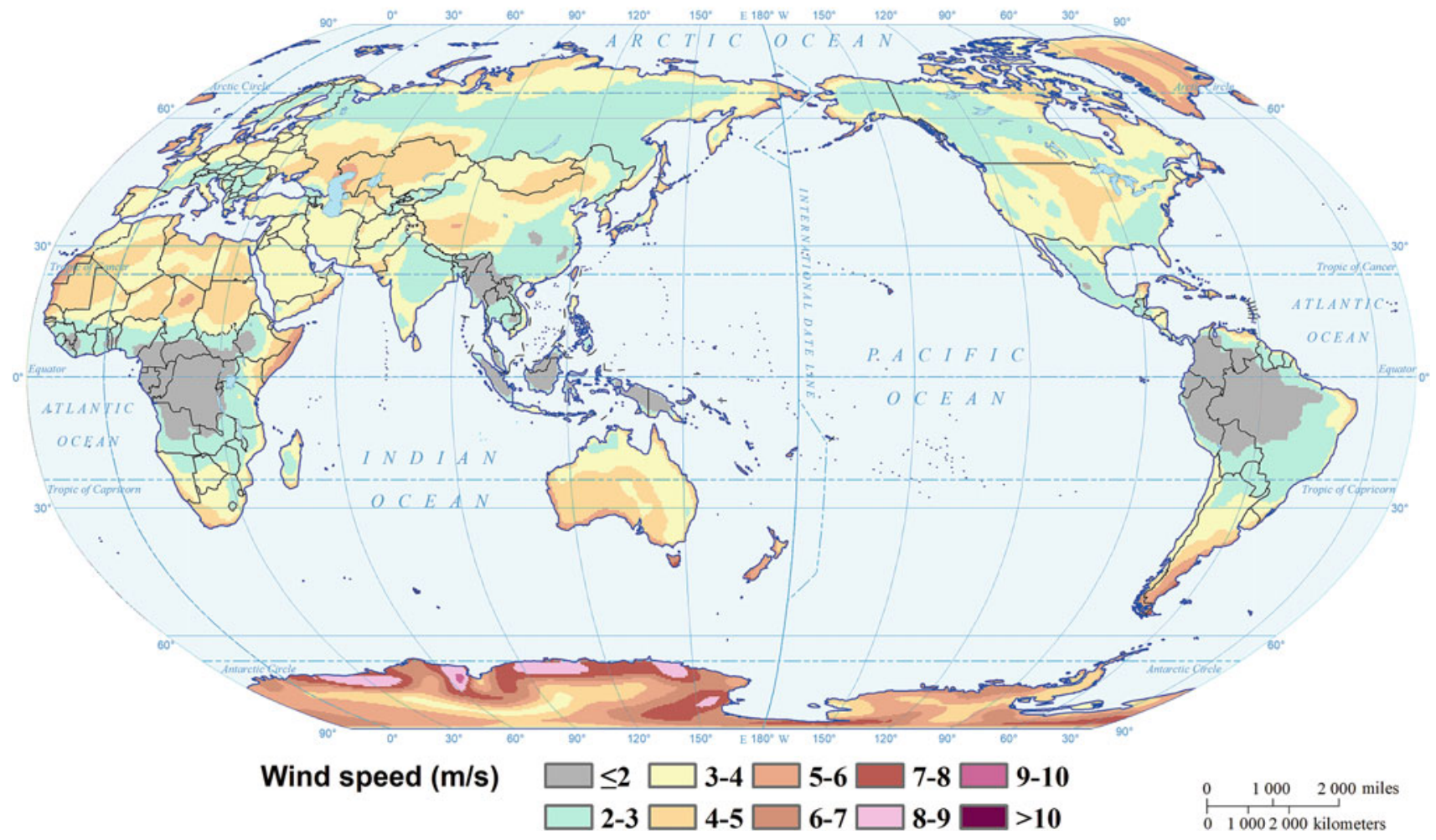

Annual mean wind speed (2030s, RCP4.5)

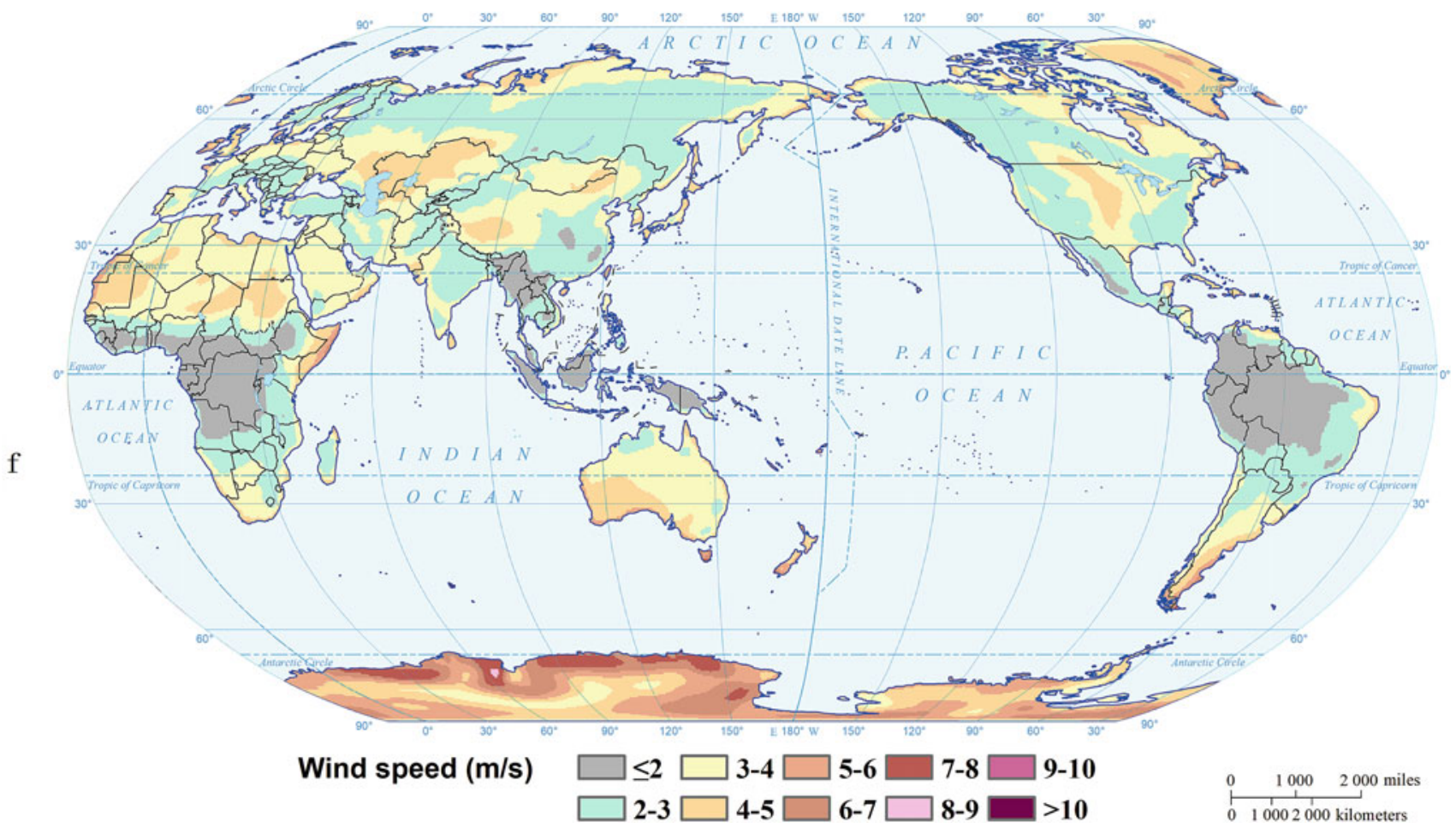


Annual mean wind speed (2030s, RCP8.5)

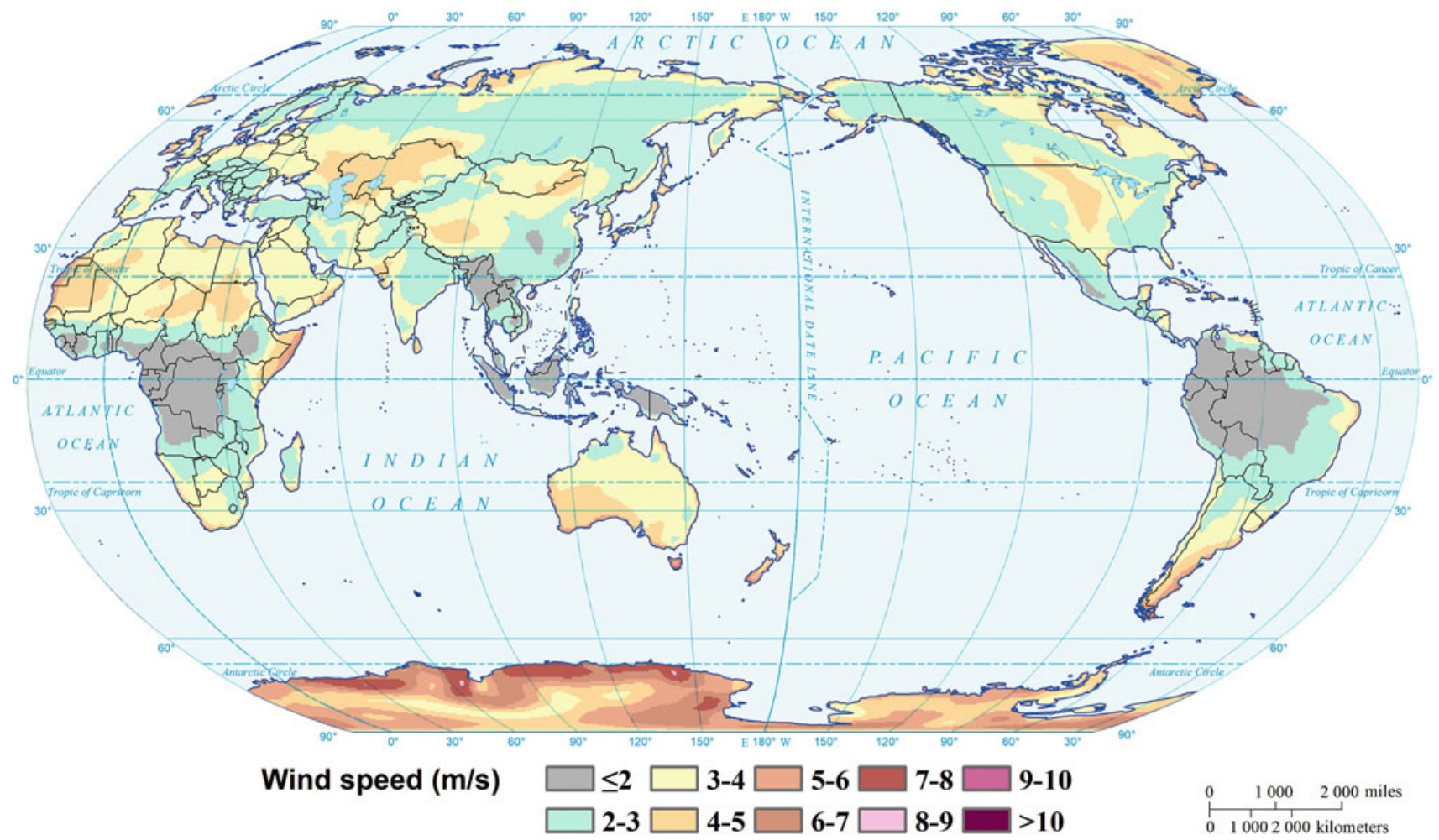

Annual mean wind speed (2050s, RCP2.6)

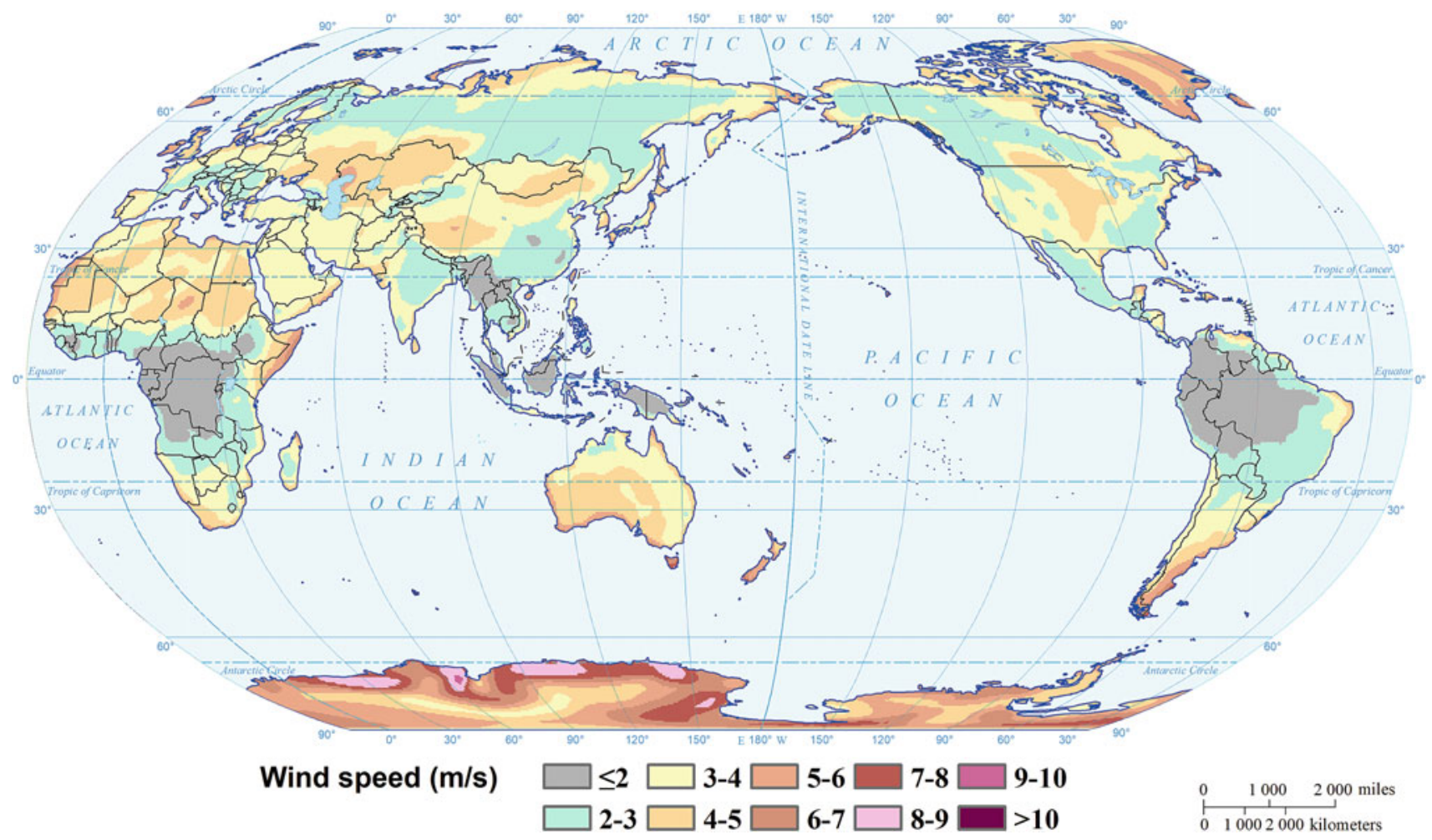


Annual mean wind speed (2050s, RCP4.5)

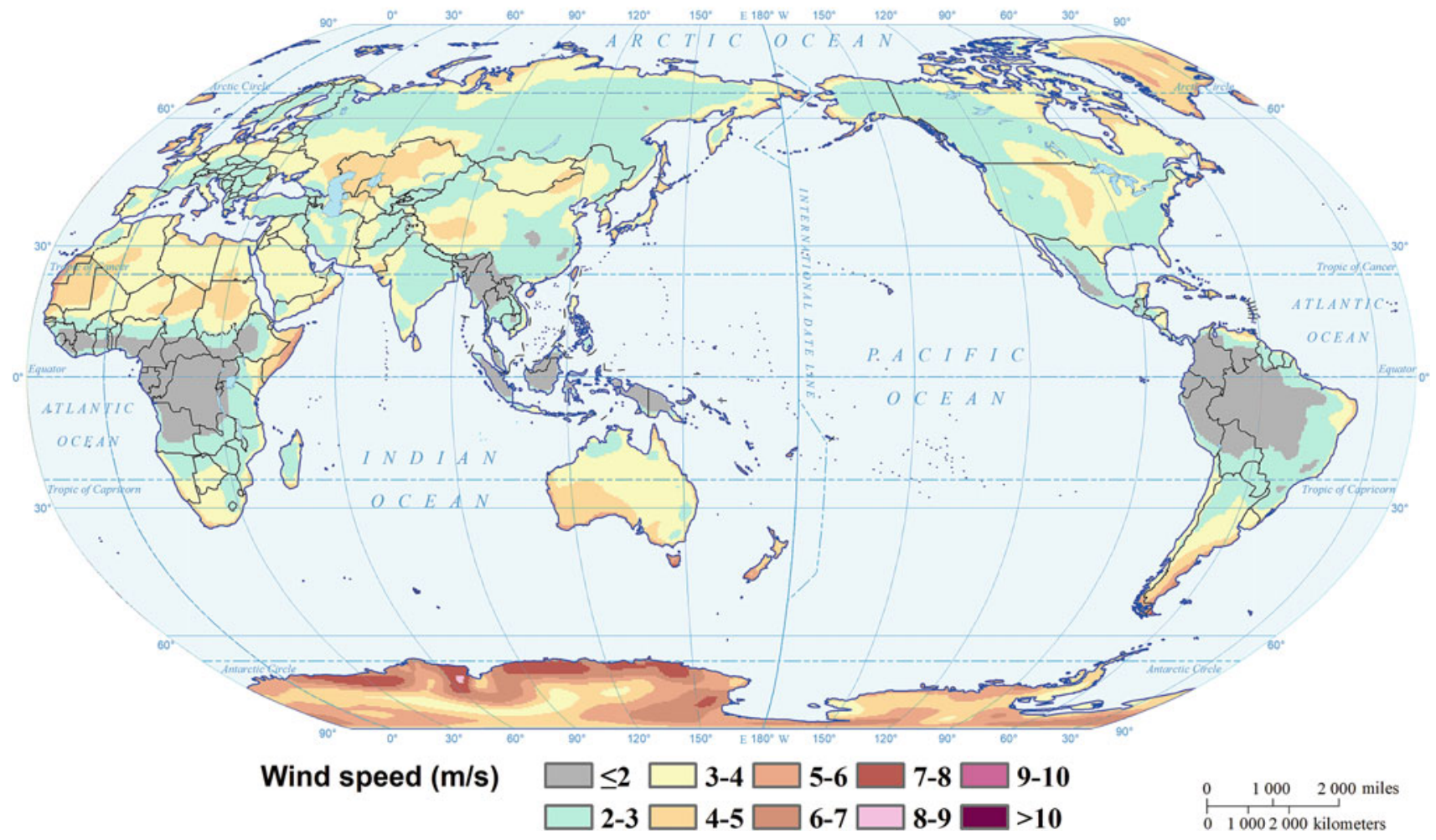

Annual mean wind speed (2050s, RCP8.5)

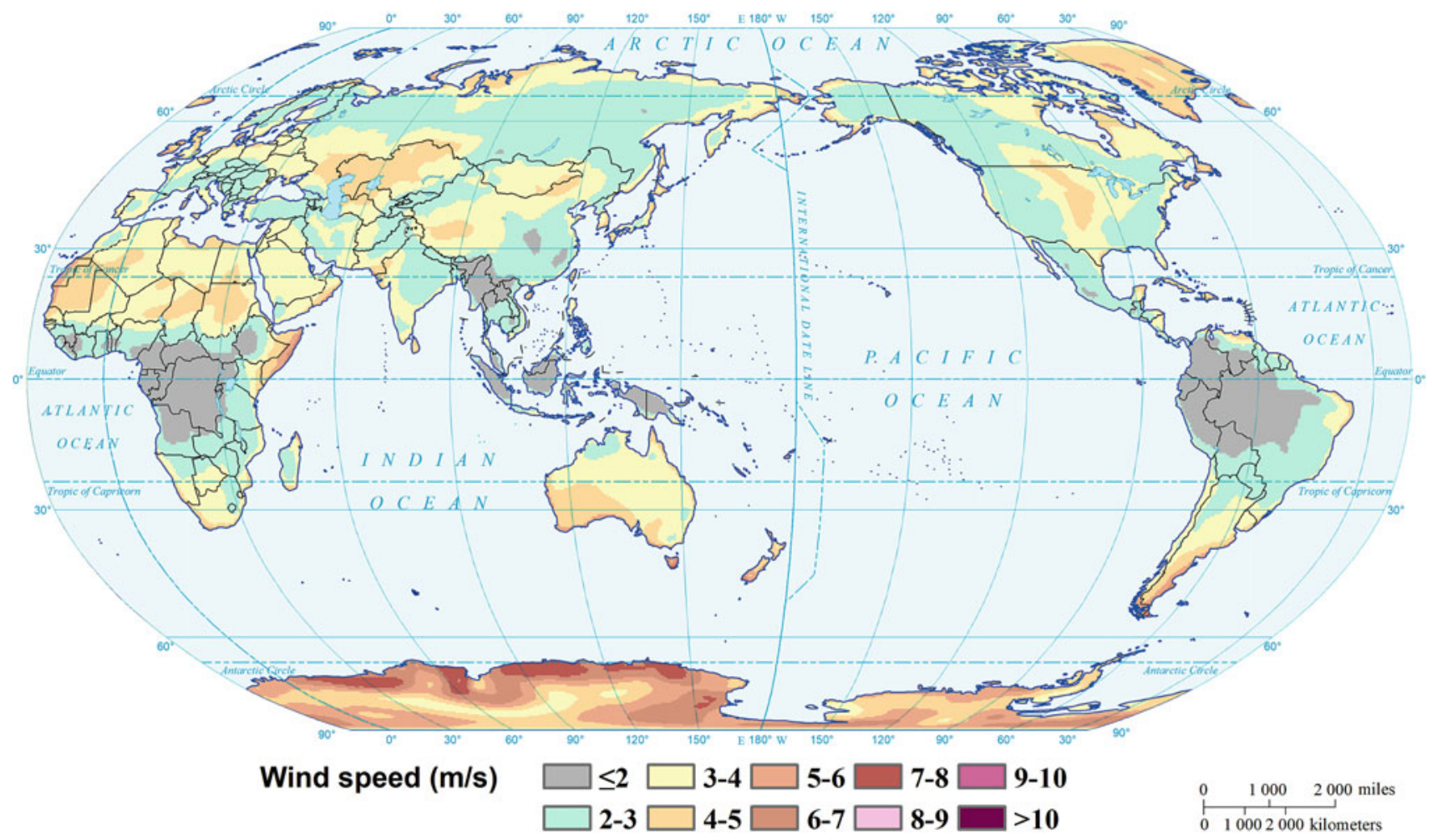




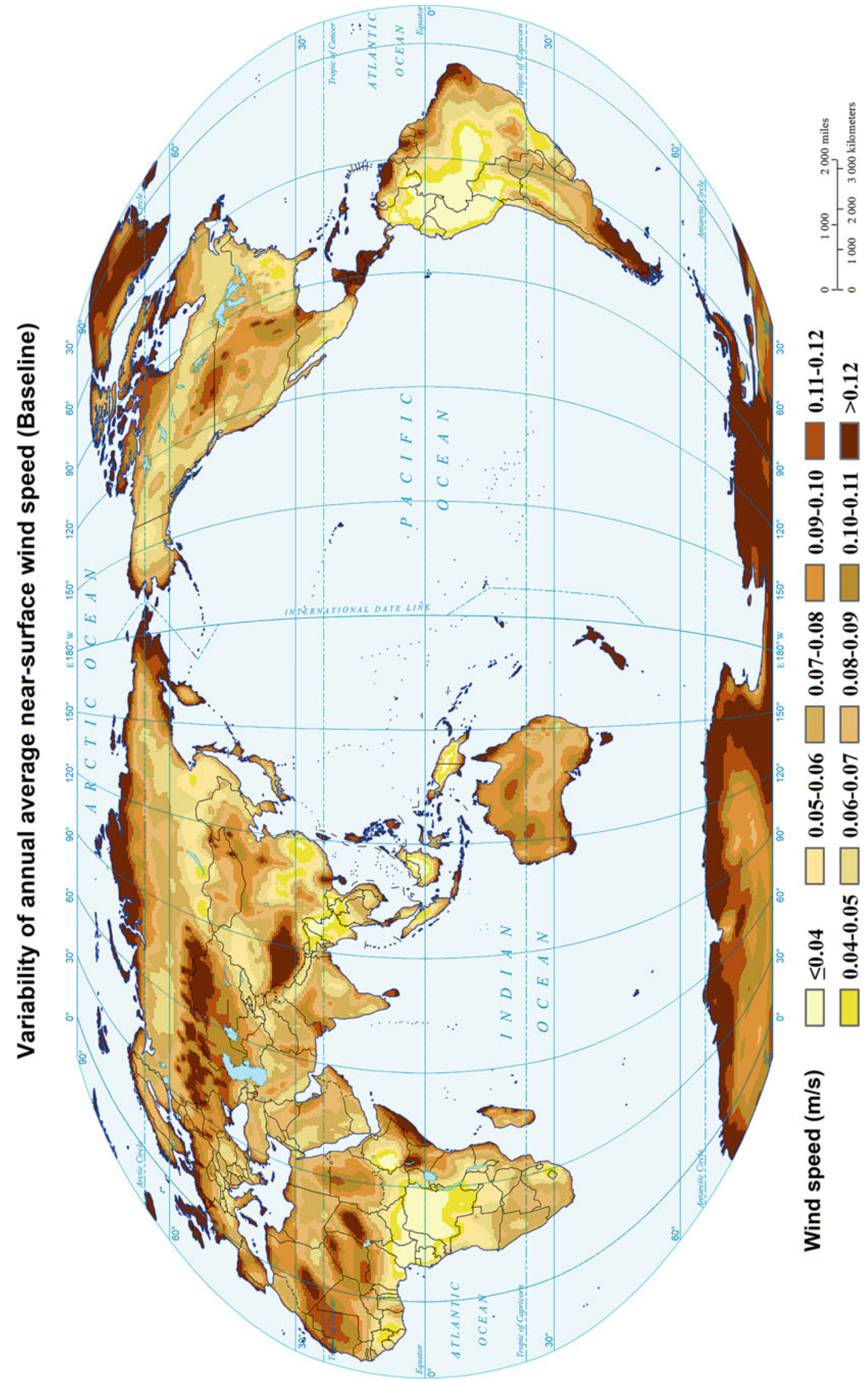


Variability of annual average near-surface wind speed (2030s, RCP2.6)

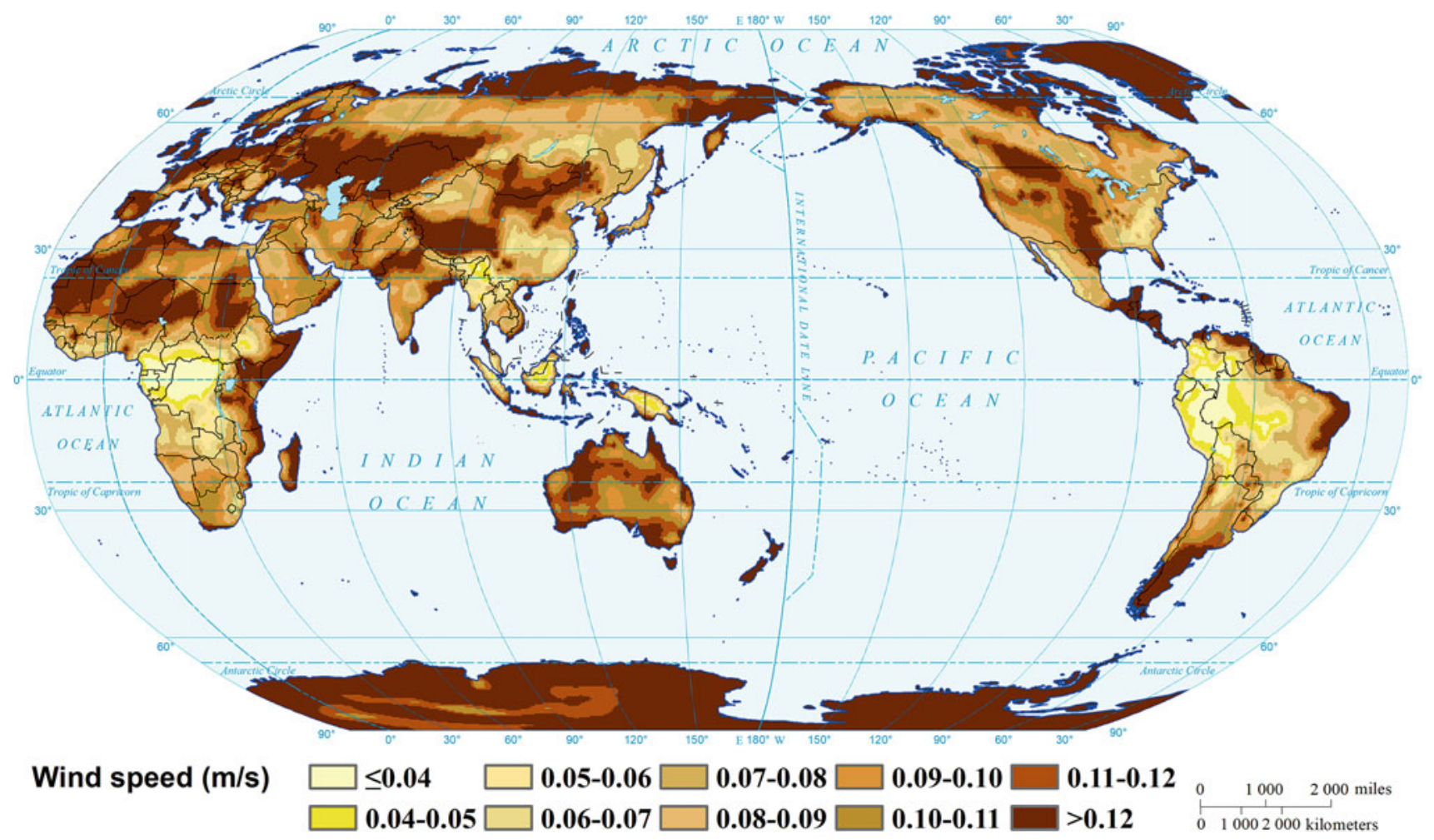

Variability of annual average near-surface wind speed (2030s, RCP4.5)

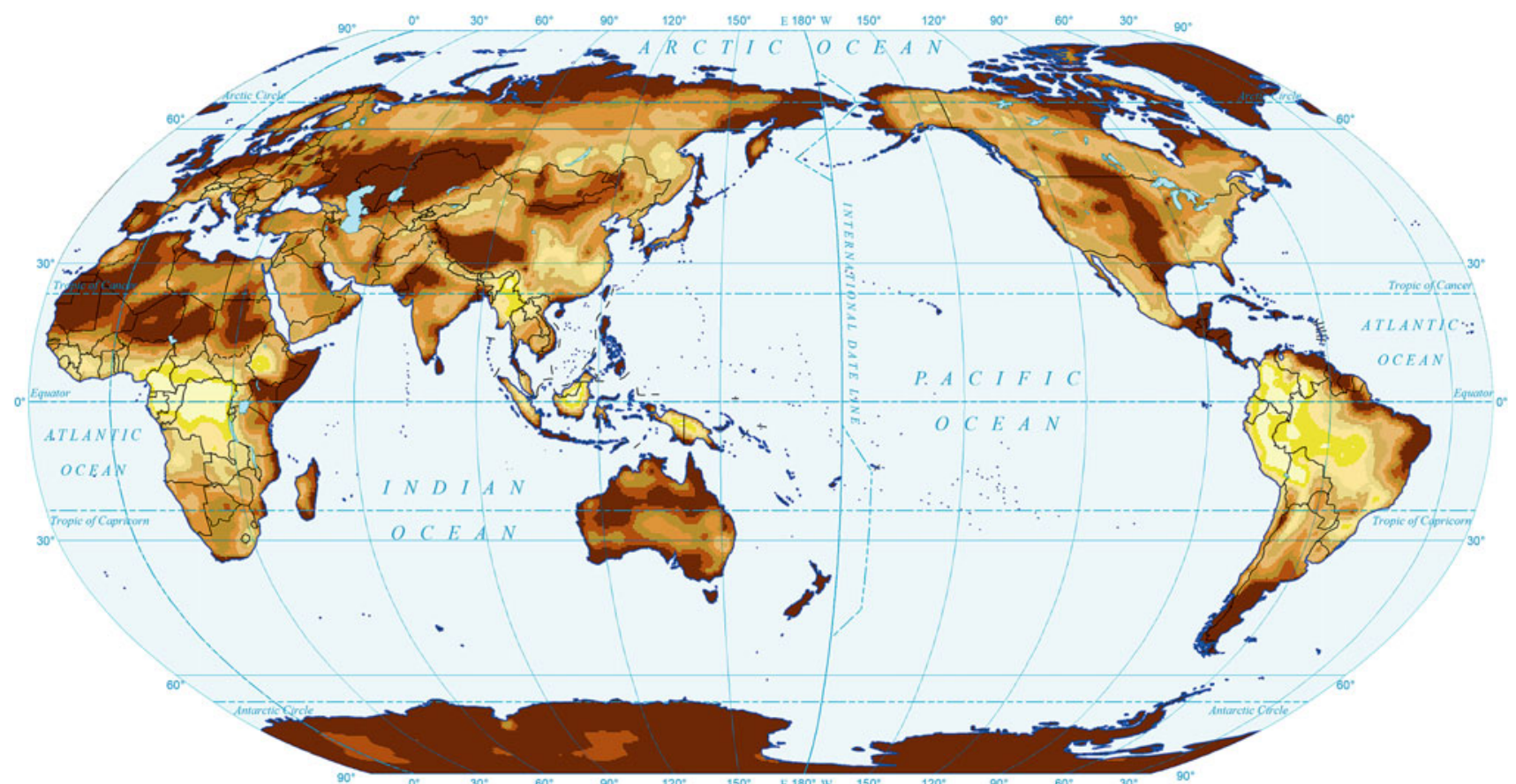

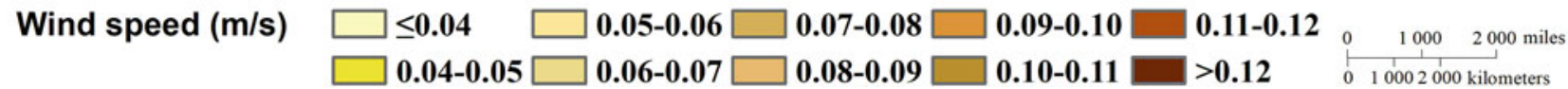


Variability of annual average near-surface wind speed (2030s, RCP8.5)

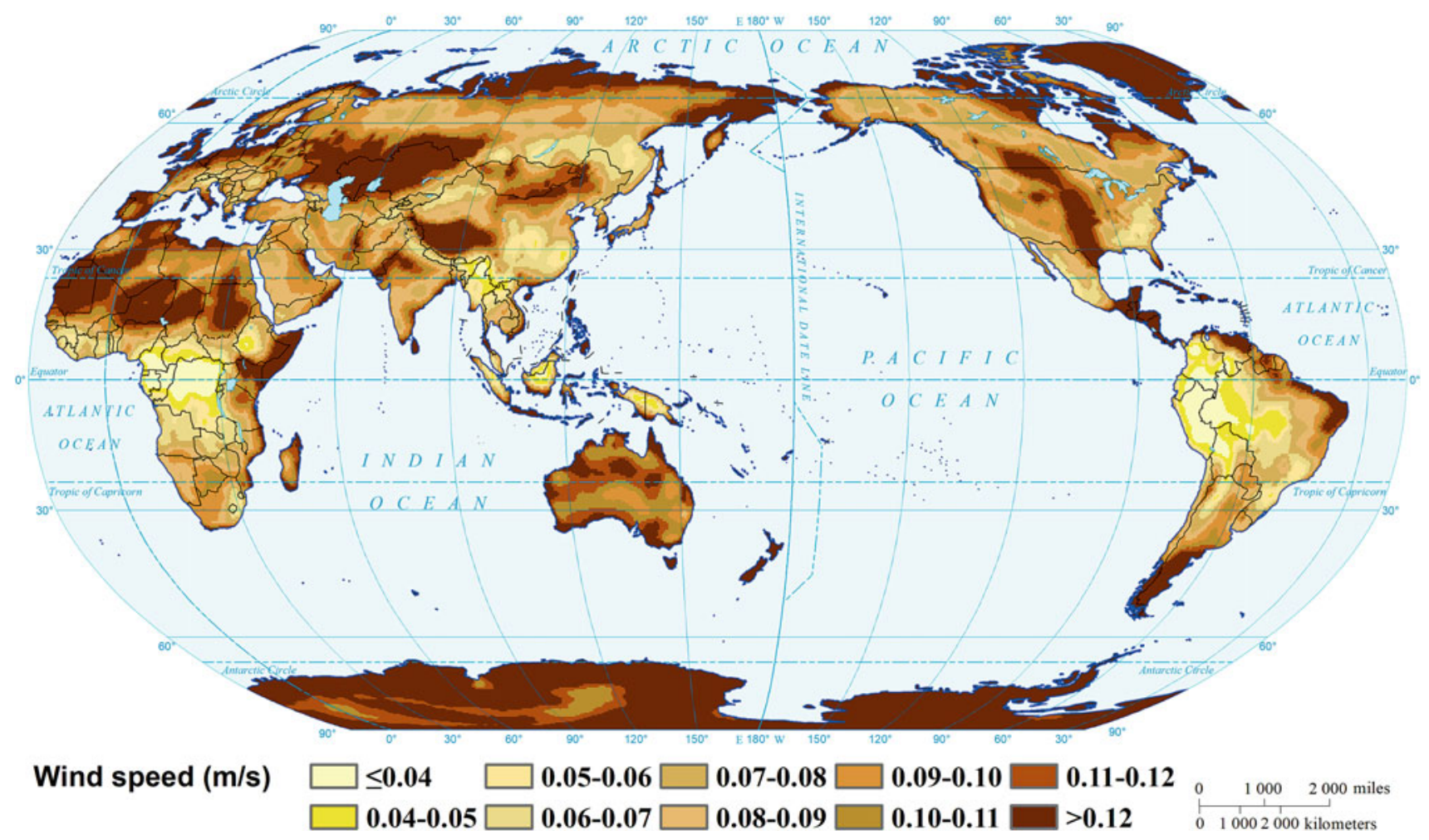

Variability of annual average near-surface wind speed (2050s, RCP2.6)

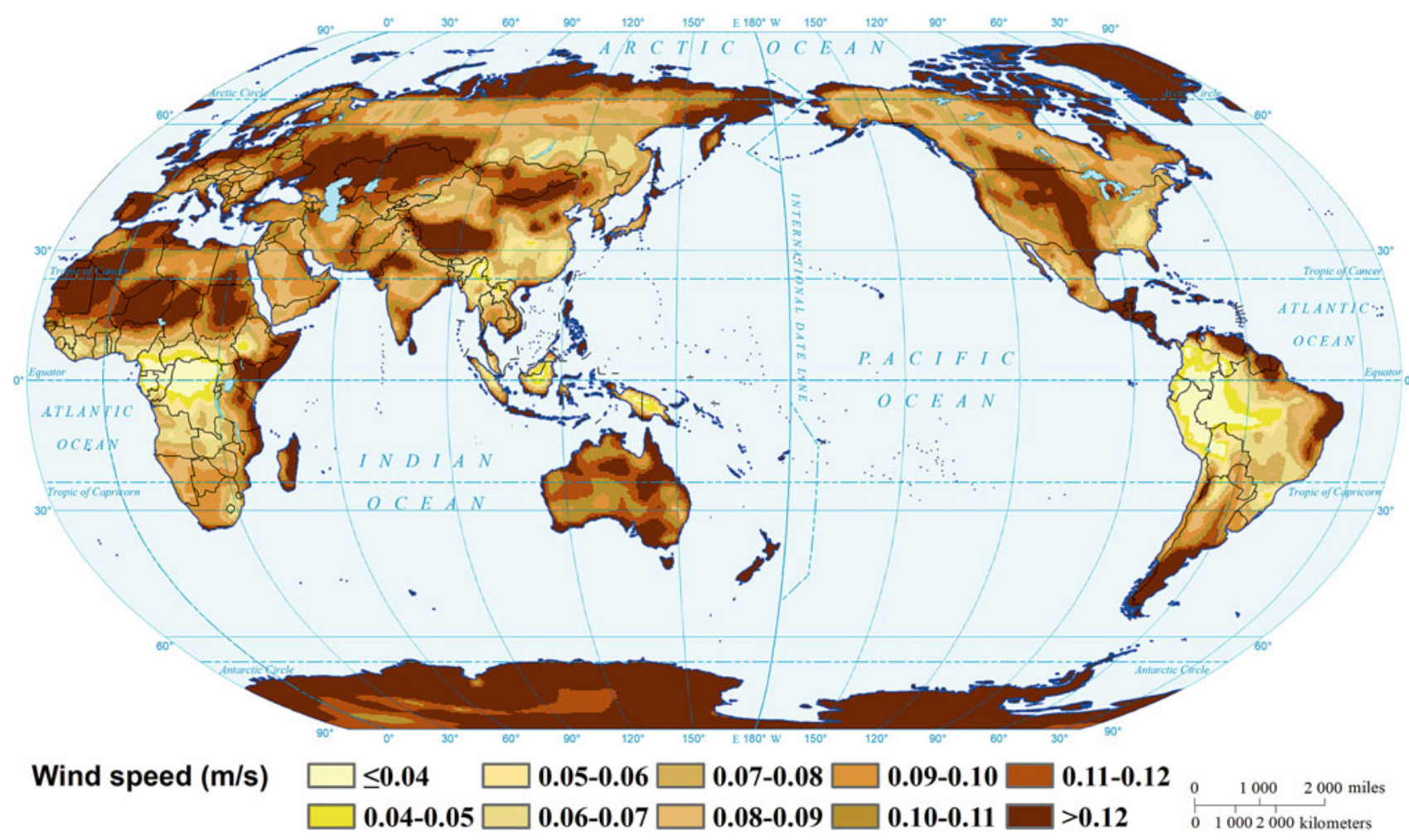


Variability of annual average near-surface wind speed (2050s, RCP4.5)

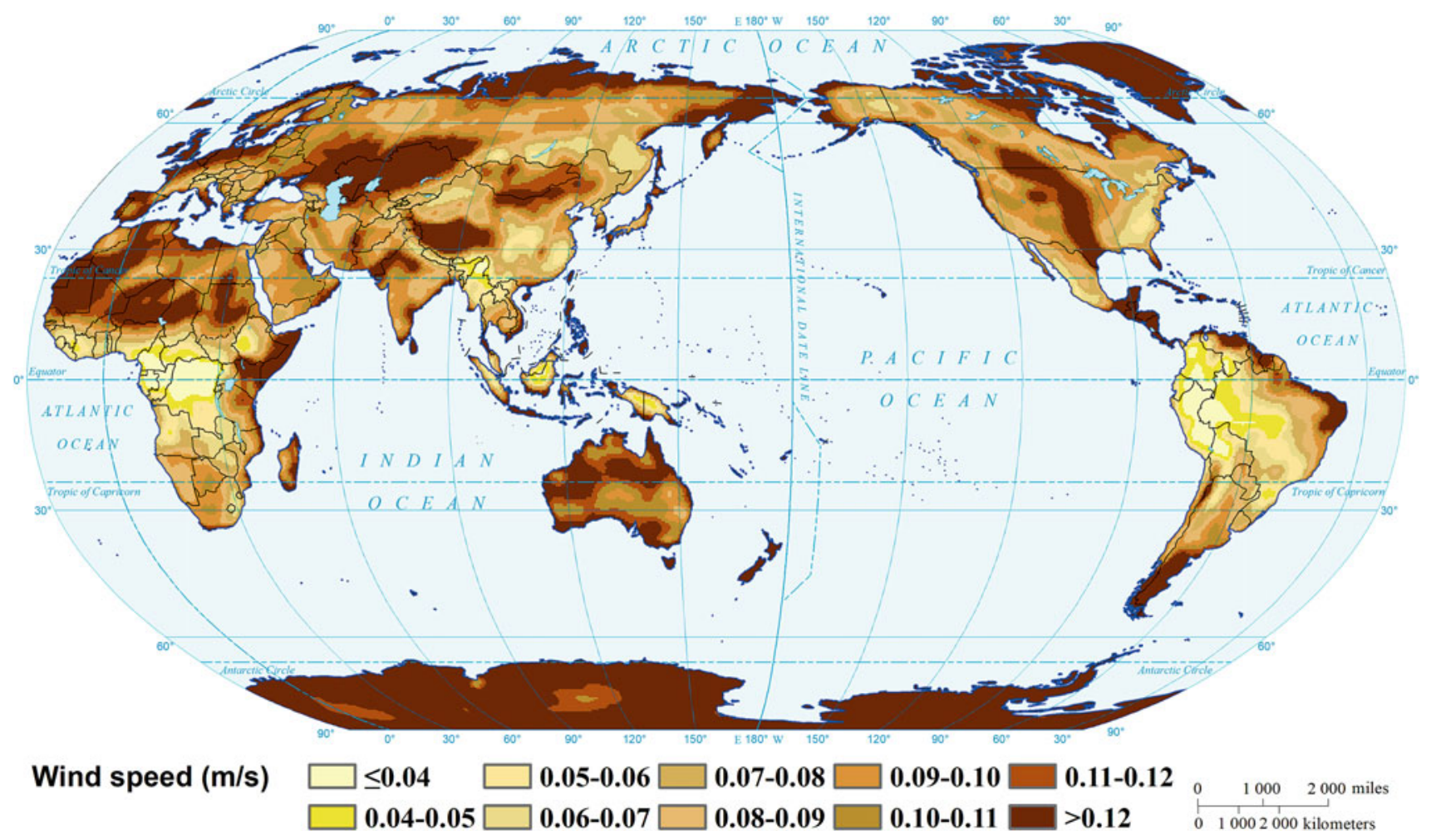

Variability of annual average near-surface wind speed (2050s, RCP8.5)

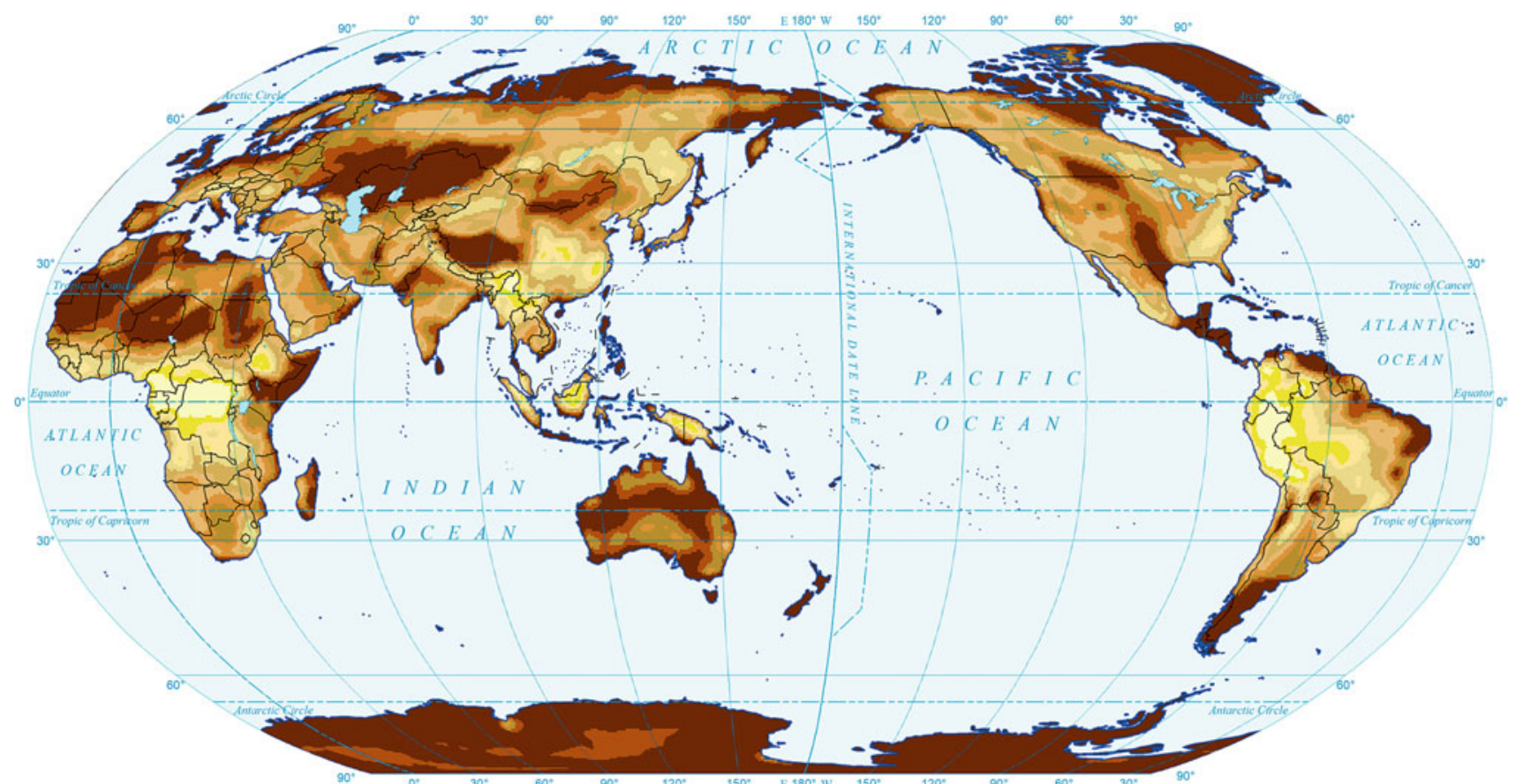

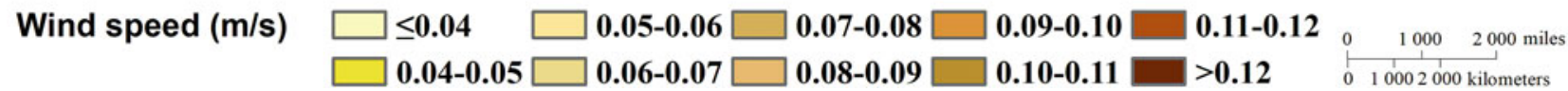




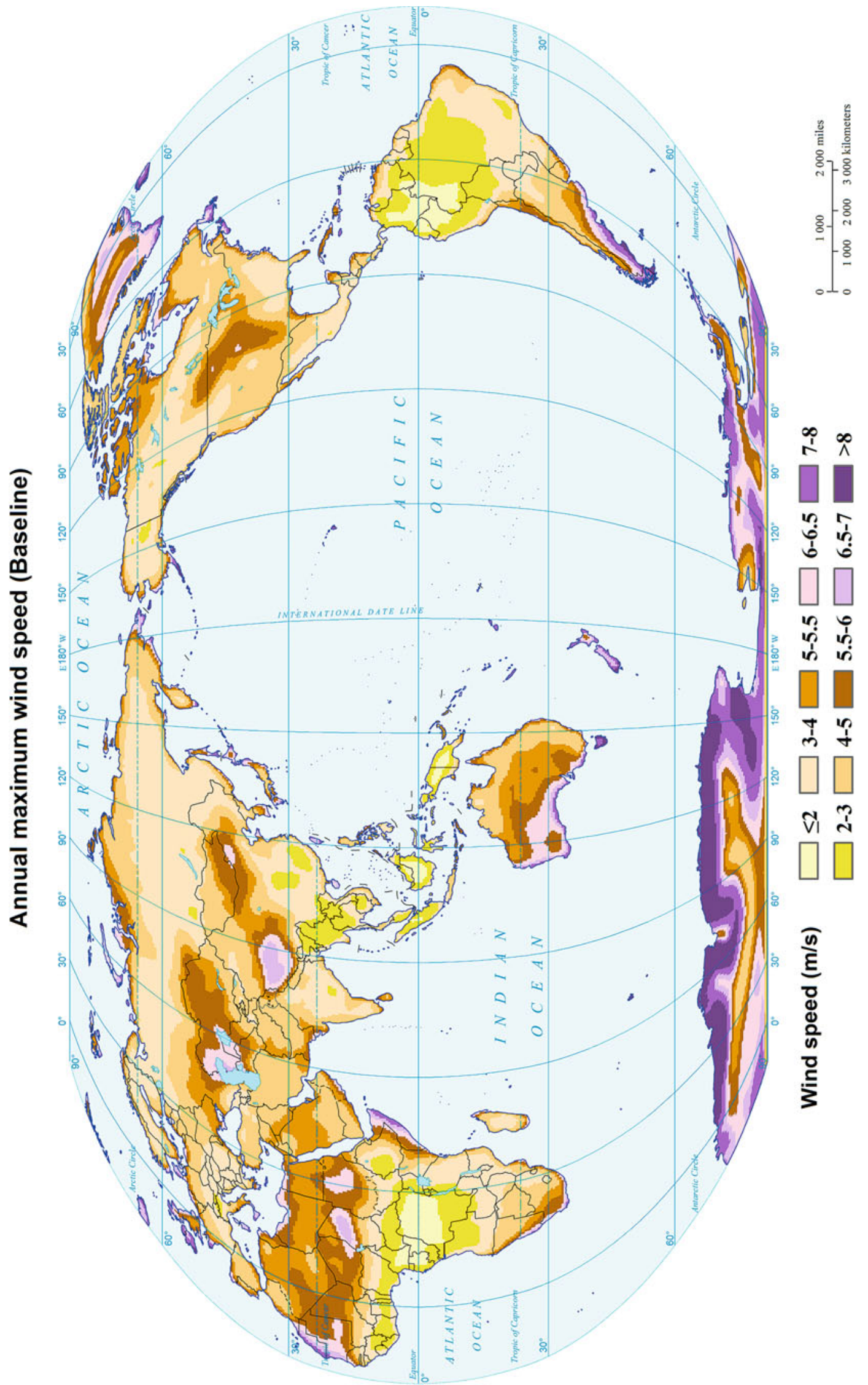


Annual maximum wind speed (2030s, RCP2.6)

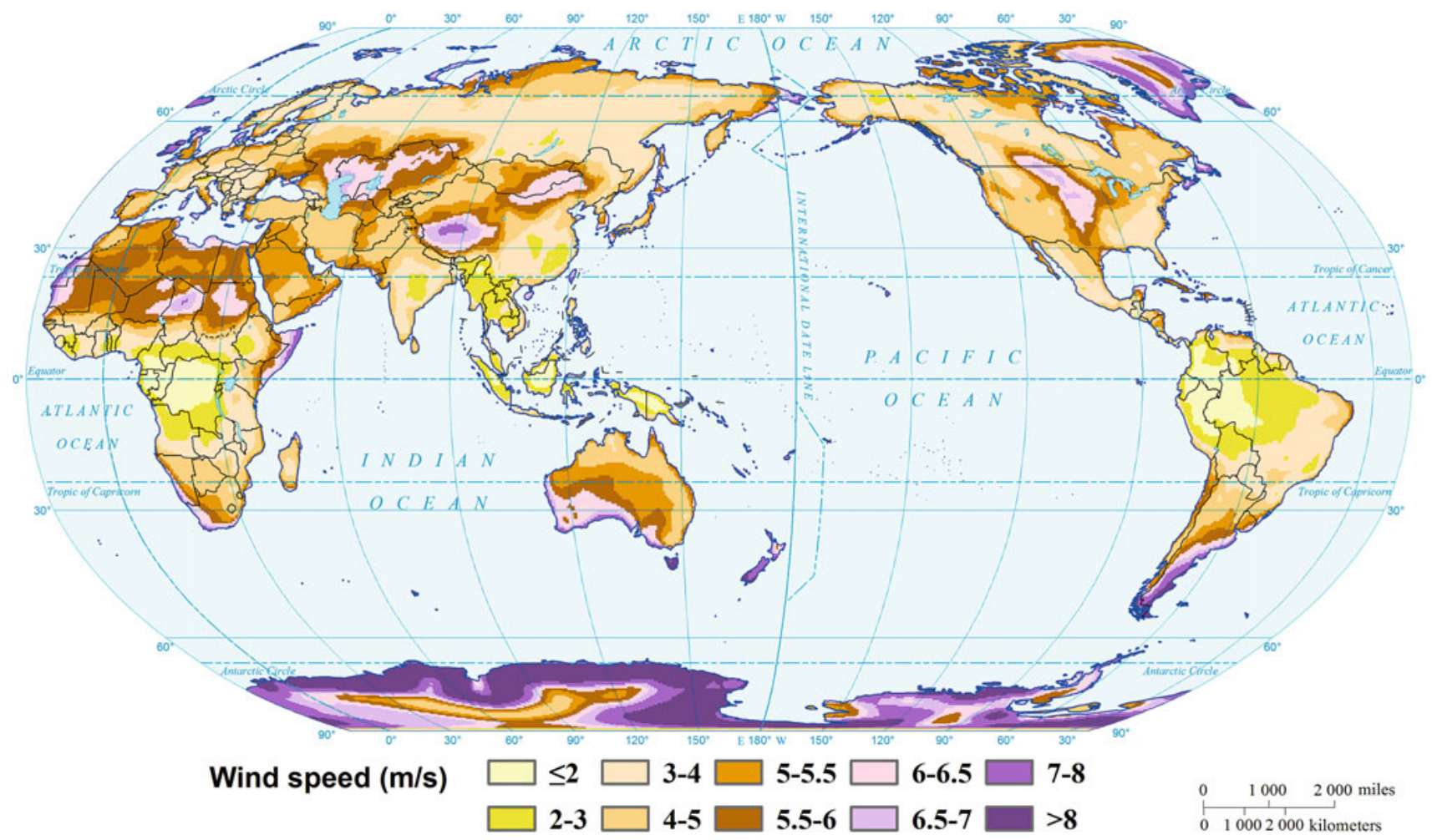

Annual maximum wind speed (2030s, RCP4.5)

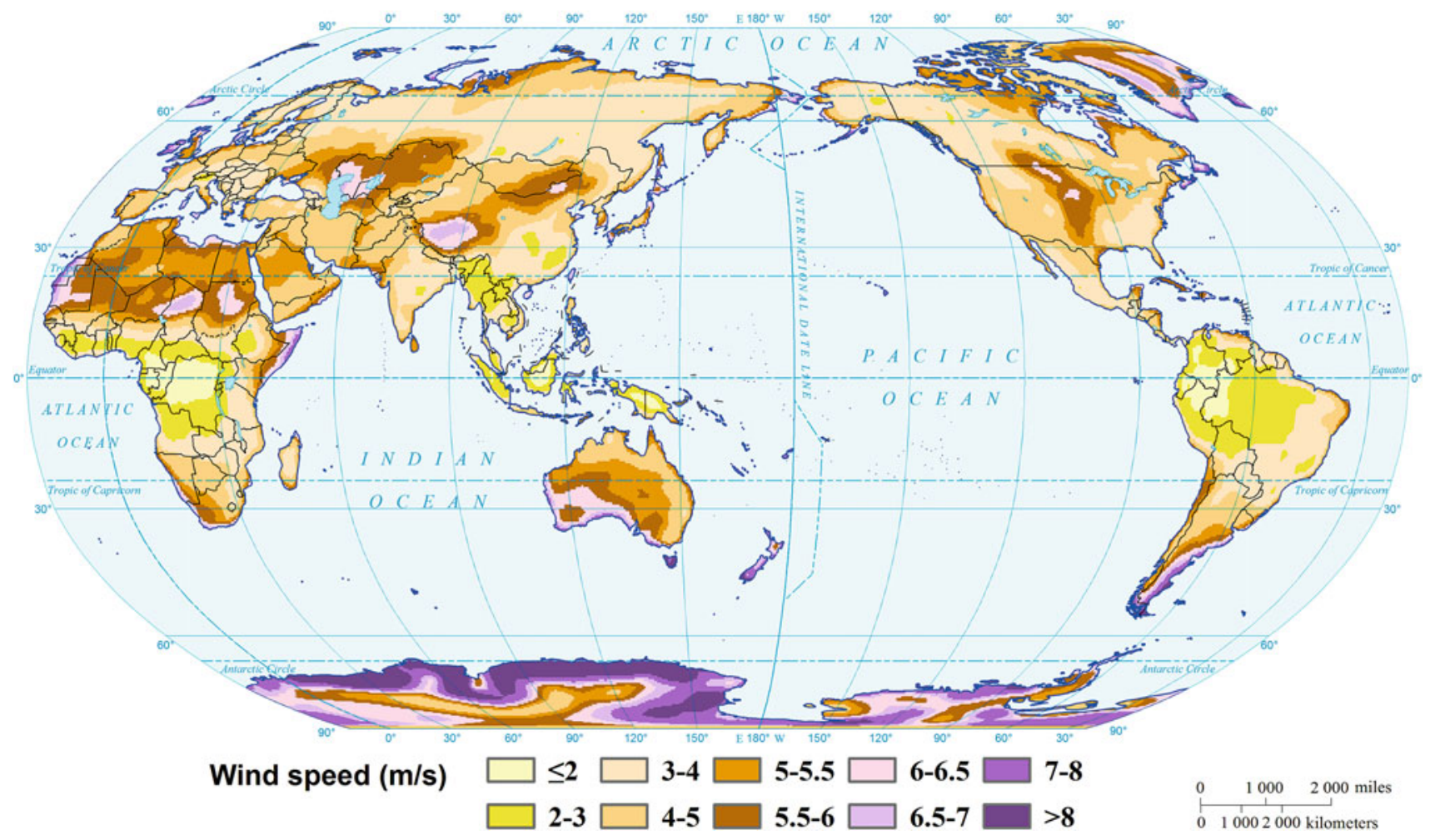


Annual maximum wind speed (2030s, RCP8.5)

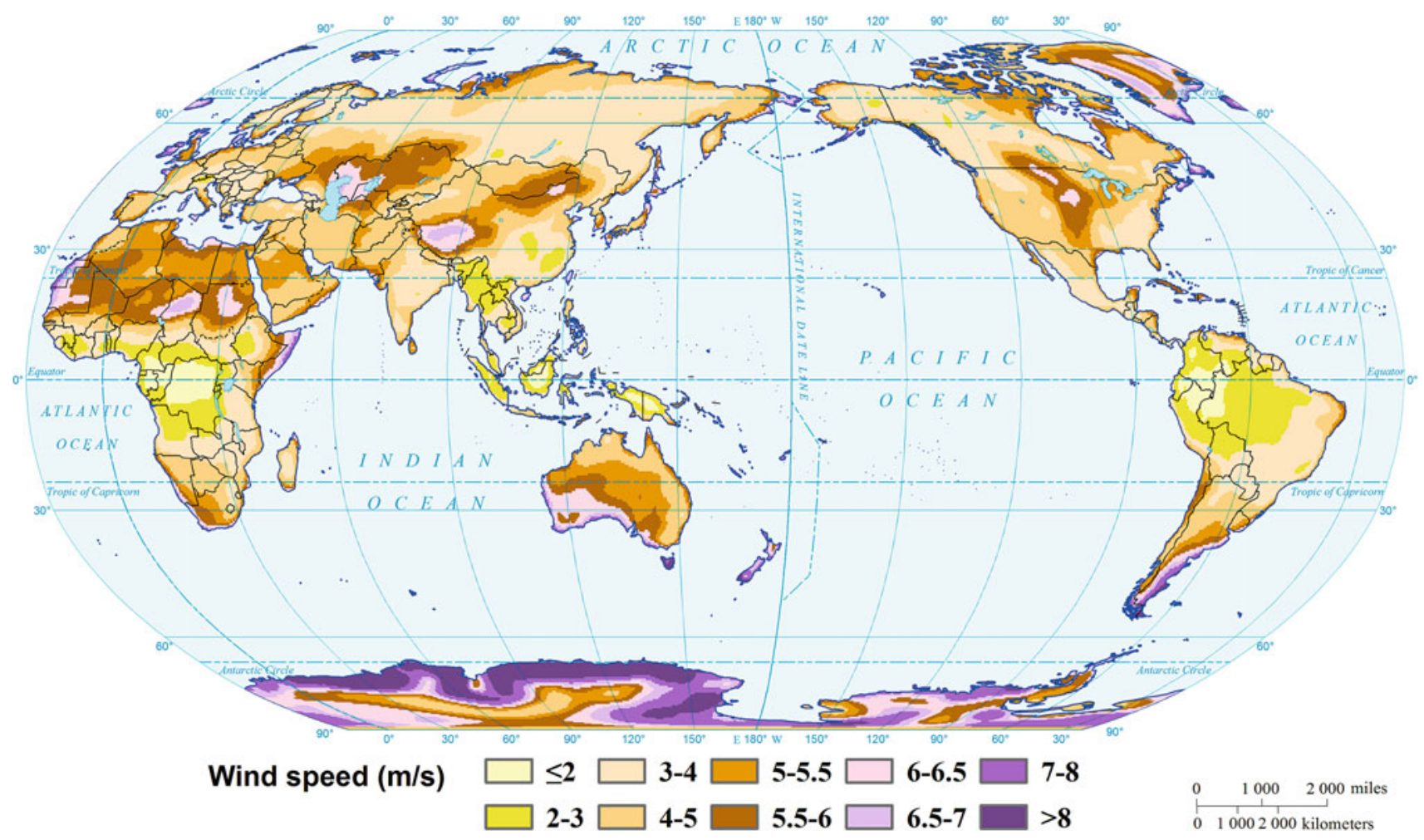

Annual maximum wind speed (2050s, RCP2.6)

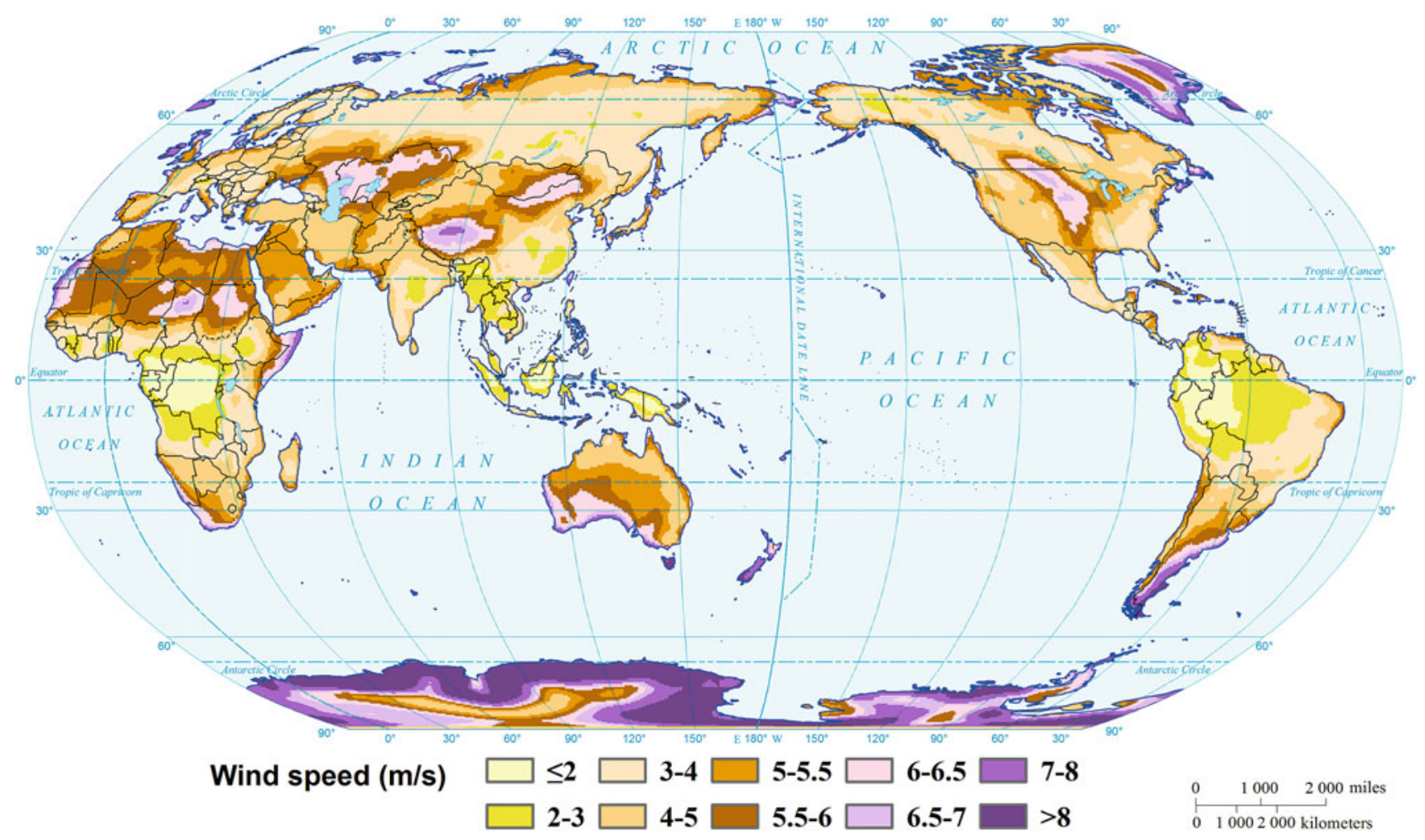


Annual maximum wind speed (2050s, RCP4.5)

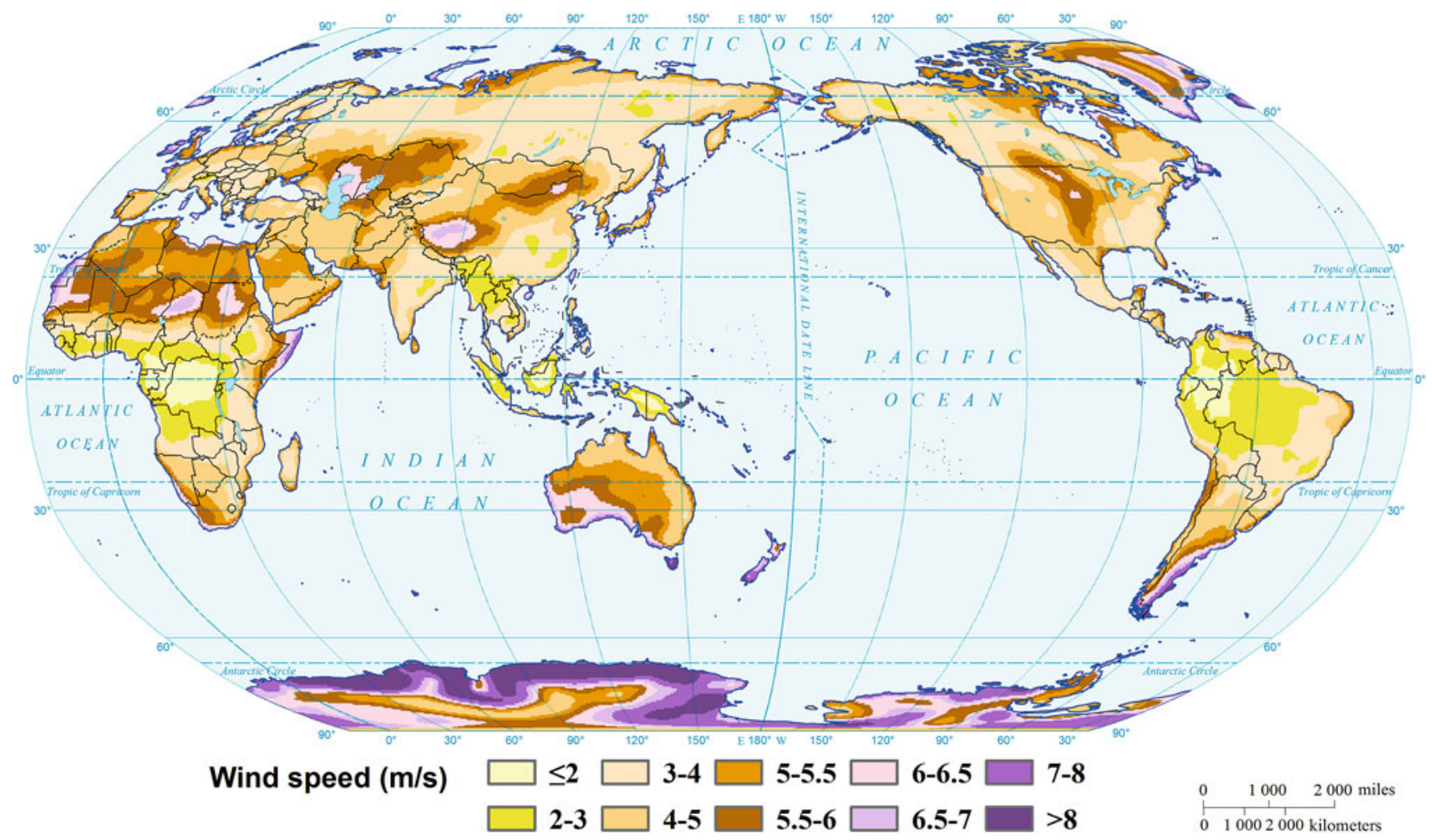

Annual maximum wind speed (2050s, RCP8.5)

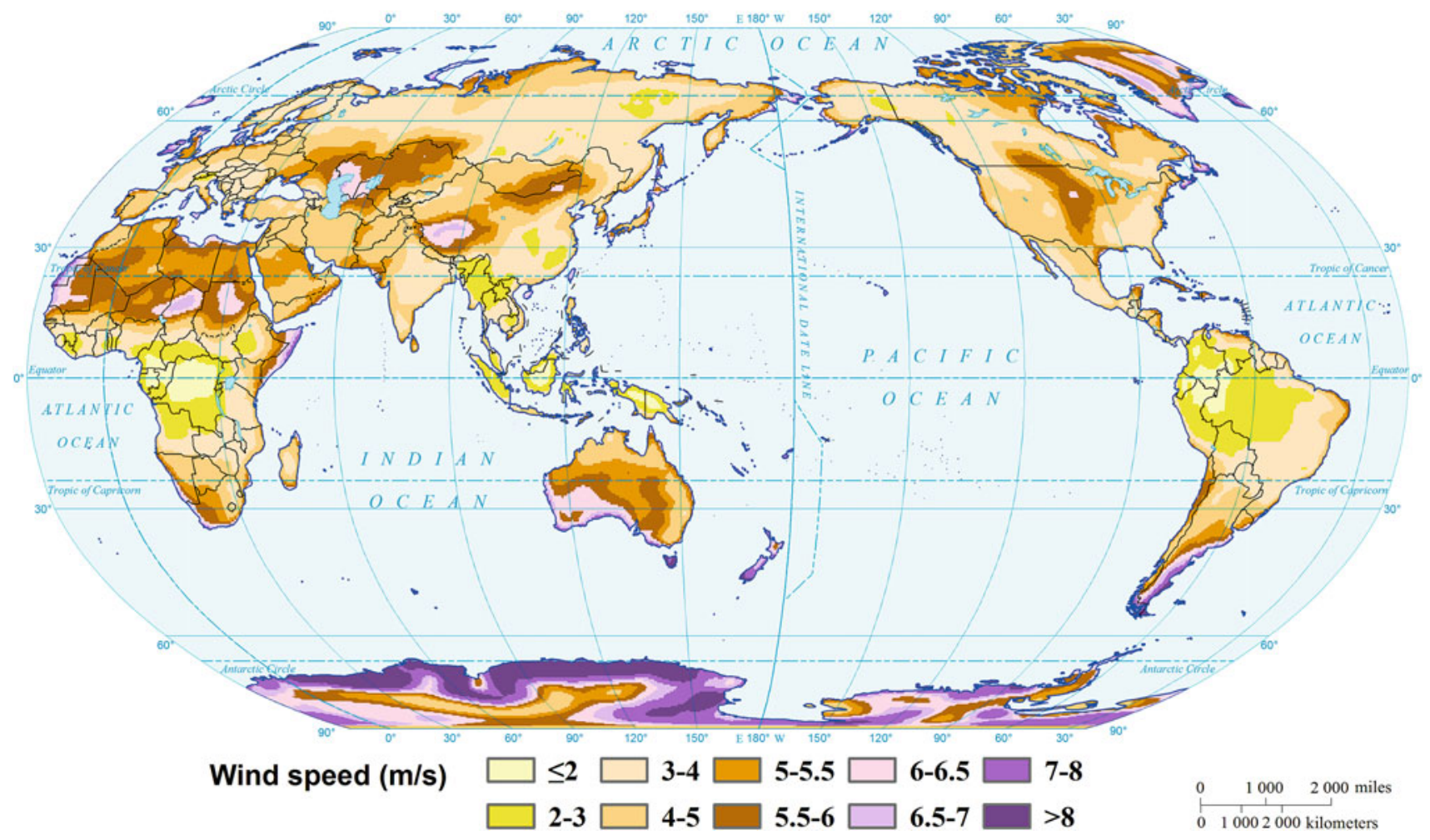




\section{References}

Giorgi, F., and X. Bi. 2005. Regional changes in surface climate interannual variability for the 21 st century from ensembles of global model simulations. Geophysical Research Letters 32: L13701.

Krishnan, A., and P.K. Bhaskaran. 2019. Performance of CMIP5 wind speed from global climate models for the Bay of Bengal region. International Journal of Climatology. https://doi.org/10.1002/joc. 6404.

Kumar, D., V. Mishra, and A.R. Ganguly. 2015. Evaluating wind extremes in CMIP5 climate models. Climate Dynamics 45: 441453.

Pryor, S.C., R.J. Barthelmie, N.E. Clausen, M. Drews, N. MacKellar, and E. Kjellstrom. 2012. Analyses of possible changes in intense and extreme wind speeds over northern Europe under climate change scenarios. Climate Dynamics 38: 189-208.

Tian, Q., G. Huang, K. Hu, and D. Niyogi. 2019. Observed and global climate model based changes in wind power potential over the Northern Hemisphere during 1979-2016. Energy 167: 1224-1235.

Vautard, R., J.L. Cattiaux, P. Yiou, J.N. Thepaut, and P. Ciais. 2010. Northern Hemisphere atmospheric stilling partly attributed to an increase in surface roughness. Nature Geoscience 3 (11): 756-761.

Wu, J., J. Zha, D. Zhao, and Q. Yang. 2018. Changes in terrestrial near-surface wind speed and their possible causes: An overview. Climate Dynamics 51: 2039-2078.

Yan, Z., S. Bate, R.E. Chandler, V. Isham, and H. Wheater. 2002. An analysis of daily maximum wind speed in Northwestern Europe using generalized linear models. Journal of Climate 15: 2073-2088.
Open Access This chapter is licensed under the terms of the Creative Commons Attribution 4.0 International License (http:// creativecommons.org/licenses/by/4.0/), which permits use, sharing, adaptation, distribution and reproduction in any medium or format, as long as you give appropriate credit to the original author(s) and the source, provide a link to the Creative Commons license and indicate if changes were made.
The images or other third party material in this chapter are included in the chapter's Creative Commons license, unless indicated otherwise in a credit line to the material. If material is not included in the chapter's Creative Commons license and your intended use is not permitted by statutory regulation or exceeds the permitted use, you will need to obtain permission directly from the copyright holder. 